\title{
New system for real time study of in vivo migration and differentiation of stem cells
}

\author{
Siddiqul Haque · Günter R. Fuhr
}

Received: 23 June 2010/Accepted: 11 August 2010/Published online: 15 September 2010

(C) The Author(s) 2010. This article is published with open access at Springerlink.com

\begin{abstract}
Cell therapy is a promising and emerging field for the treatment of human diseases. However, to understand and optimize cell therapy, the inability to track the cell transplants in vivo remains a major problem. Most cell transplantation techniques involve the use of histological analysis to evaluate cell transfection, proliferation, and migration after sacrifice. In this literature, for the first time an in vivo model has been developed to study stem cells. Explantation culture of chicken embryo into surrogate shells has been modified for high resolution and long term imaging. A special long distance fluorescence microscope and micromanipulation systems has been developed for in vivo application specially aiming for the injection and tracking of fluorescence labeled cells into chicken embryo and track them. By using the developed system, it was possible to image the whole period of embryonic development of chicken embryo.
\end{abstract}

\section{Introduction}

The discovery of stem cell raised new hopes for regenerative and transplantation therapy as well as for tissue

Electronic supplementary material The online version of this article (doi:10.1007/s00542-010-1127-4) contains supplementary material, which is available to authorized users.

S. Haque $(\bowtie)$

Cell Biology and Applied Virology,

Fraunhofer Institute for Biomedical Engineering,

Ensheimer Str. 48, 66386 St Ingbert, Germany

e-mail: siddiqul.haque@yahoo.com

G. R. Fuhr

Fraunhofer Institute for Biomedical Engineering,

Ensheimer Str. 48, 66386 St Ingbert, Germany engineering. Multi linage differentiation of these cells in vitro shows their therapeutic potential. Transplantation of stem or progenitor cells is a revolutionary new technique proposed for the treatment of various injured tissues or organs (Clarke et al. 2000; Dowell et al. 2003; Fuchs and Segre 2000; Gibbs 2006; Goldenthal and Marin-Garcia 2003; He et al. 2003; Jiang et al. 2002; Keller and Snodgrass 1999; Kuehnle and Goodell 2002; McKay 2000; Niklason and Langer 2001; Paul et al. 2002; Reubinoff et al. 2000; Senior 1999). Because cells can be isolated from different tissues, expanded in vitro, and replace or repair defective endogenous cell populations, they offer new promise for tissue repair and disease correction (Kuehnle and Goodell 2002; McKay 2000; Taylor et al. 1997; Tsonis 2002). Cell therapy appears to be a promising field for the treatment of human diseases. As part of this new field, transplantation of smooth muscle cells has undergone extensive investigation in recent years as a potential therapy, mainly for the repair of aneurysms (Allaire et al. 2002), myocardial ischemia (Yoo et al. 2000) or for cardiac graft (Ozawa et al. 2002). The fetal brain, characterized by active neurogenesis, has been suggested to be a promising source of therapeutic neural stem cells (Flax et al. 1998). Never the less, questions have been raised regarding the safety of stem cell therapy. A recent human study demonstrated the tumour development after stem cell therapy (Amariglio et al. 2009). These insights show the necessities to develop appropriate and precise methods for experimental investigations of migration and differentiation of stem cells in vivo. However, most experimental investigations regarding stem cell differentiation are in vitro. The question remains whether these results in vitro can be applied in vivo situations or not. Most, if not all, differentiated cells derived from diverse tissue sources lose their specialized features and dedifferentiate when grown under traditional two-dimensional cell culture 
conditions (Anders et al. 2003; Wang et al. 1998; Weaver et al. 1997; Wolf et al. 2003). It is, therefore, necessary to search for newer methods for the in vivo study of stem cells.

Inability to track the cell transplants remains a major problem that must still be overcome to understand and optimize cell therapy. It is difficult to follow the fate of the implanted cells in a living organism. In fact, most cell transplantation techniques involve the use of histological analysis to evaluate cell transfection, proliferation, and migration after sacrificing the animal (Kocher et al. 2001; Orlic et al. 2003; Toma et al. 2002). Following the status of stem cells in vivo is critical if therapy is to be optimized or evaluated. Progenitor cells labelled with Super Paramagnetic Iron Oxide Nanoparticle (SPION) allows for threedimensional (3D), high-resolution, whole body imaging and tracking of cells in vivo. It is an ideal technique to determine the fate of cells after transplantation and migration of cells after injection, without the need for tissue biopsies and histological assessment. In nondividing human mesenchymal stem cells, endosomal iron nanoparticles could be detected after 7 weeks; however, in rapidly dividing cells, intracellular iron had disappeared by five to eight cell divisions (Arbab et al. 2003).

Interspecies transplantation has permitted the study of both differentiation and therapeutic potential of stem cells. Several systems have been used to study the behavior of adult or embryonic stem cells in the postgastrulation embryo. For example, human adult bone marrow stromal stem cells were injected into sheep embryos, and differentiation of these cells was followed in utero (Liechty et al. 2000). However, such experiments involving mammals are very expensive, complicated and require special facilities. The chick embryo is a well-characterized and accessible experimental system for study of inductive interactions and differentiation in development. Several studies have shown that mammalian cells and tissues transplanted to avian embryos can respond to local cues and develop into tissues appropriate to their location in the host (Fontaine-Perus et al. 1997; Goldstein et al. 2002; White and Anderson 1999). This has been used for different applications of the CAM model such as angiogenesis and antiangiogenesis (Ribatti et al. 2000, 2001; Richardson and Singh 2003), wound healing (Ribatti et al. 1996), tissue engineering (Borges et al. 2003), biomaterials and implants (Klueh et al. 2003; Valdes et al. 2002; Zwadlo-Klarwasser et al. 2001), testing therapeutics on human leukemia (Taizi et al. 2006), short-term transplantation of cryopreserved human ovarian tissue (Martinez-Madrid et al. 2009) and biosensors (Valdes et al. 2003). Chick embryos have also been used as a host for the study of the migration of mouse embryonic stem cells with and without genetic manipulation (Beauvais-Jouneau et al. 1999). The advantage of using the chick embryo rather than teratomas in rodents is the ability to follow human ES cell development in a normal embryonic environment, as opposed to the lessnatural environment of adult murine tissues.

Explantation culture of chicken embryos in surrogate shells is an established method for the production of transgenic birds and allows imaging access to the spectacular world of intravital processes during embryonic development. Rowlett and Simkiss (1987) first reported that 3-day pre-incubated chicken embryos inside the egg could be cultured to hatching using turkey eggshells. Later, Perry (1988) devised a complete three-step culture method for the chicken embryos from the single-cell stage obtained from the posterior region of the magnum to hatching using glass jars and chicken eggshells. The system consists of chicken embryos explanted into a surrogate shell taken from a donor egg and is closed with double layer of cling film. Explantation culture of chicken embryos in surrogate shell may allow such intravital observations with optical and other imaging methods at a very high resolution. The lack of a functional immune system of the chicken embryo before Incubation Day (ID) 17 prevents graft rejection (Martinez-Madrid et al. 2009). Implantation of stem cells from different species into the chicken embryo shows region-specific differentiation. When hematopoietic stem cells (HSCs) from adult human bone marrow was implanted into lesions of the developing spinal cord in the chicken embryo, human cells never express chicken-specific antigens, but differentiate into fullfledged neurons. The microenvironment in the regenerating spinal cord of the chicken embryo stimulates substantial proportions of adult human HSCs to differentiate into fullfledged neurons (Sigurjonsson et al. 2005). Traditionally these types of studies are conducted by histological examination of the embryos at different stage of development.

Optical imaging is an extremely sensitive method that can detect a single molecule using fluorescence techniques. Fluorescence imaging is the most sensitive approach, and it has gained great interest with the development of genetically encoded highly efficient fluorescent probes based on green fluorescence protein. Time-lapse microscopy has long been used to capture the dynamic nature of embryogenesis. Optically transparent embryos of animals such as Caenorhabditis elegans (Sulston et al. 1983), sea urchin (Ettensohn 1985; Gustafson and Wolpert 1967) and fish e.g. fundulus (Trinkaus 1996) or zebra fish (Kimmel and Law 1985), are well suited to studies of cell and tissue movement by timelapse imaging using transmitted light, e.g. differential interference contrast and various fluorescence microscopes (Cashman et al. 1997). Fluorescent time-lapse microscopy has allowed the dynamic behaviours of labelled single cells or subpopulations of cells to be tracked in vivo. Even though light cannot penetrate through the hard calcareous eggshell, optical methods can be applied in explantation culture. Since the embryo remains optically translucent in early stages of 
development, tracking of fluorescently labelled cells implanted in chicken embryos in real time and on line might provide valuable informations about stem cell migration and differentiation in vivo. However, short working distance objectives of traditional microscopes are inapplicable in vivo and traditional explantation culture is not suitable for optical imaging. In the present study, therefore, explantation culture system was technically modified for high resolution optical imaging, special long working distance fluorescence microscope has been constructed for in vivo application; for on line, in ovo tracking of fluorescence labelled cells implanted into a developing chicken embryo.

\section{Materials and methods}

\subsection{Preparation of the explantation culture}

The procedure for the preparation of the explantation culture in surrogate shells is described elsewhere (Perry 1988; Rowlett and Simkiss 1987). In short, donor embryos were harvested from fertilised Bantam chicken eggs and were transferred into the surrogate shells prepared from $30 \mathrm{~g}$ heavier eggs after removing the blunt pole. The open end of the surrogate shell was sealed with double layer of cling film using thin albumen as glue. The explanted embryo was incubated further at $37.5^{\circ} \mathrm{C}, 60 \%$ relative humidity and $30^{\circ}$ side to side rocking. Embryos were handled according to the guidelines of German animal protection laws [Tierschutzgesetz (TierSchG) in der Fassung der Bekanntmachung vom 18. Mai 2006 (BGBI.IS. 1206 ff. ber. S. 1313) und dem Gesetz über das öffentlische Veterinärwesen und die amtliche Lebensmittelüberwachung (VetALG) vom 19.05.1999 (§ 1 Abs. 3 Amtsbl. S 844, 851)].

\subsection{Construction of a better lid for optical imaging}

The new lid for explantation culture was constructed with Plexiglas containing a groove filled with medical grade silicone (NuSil Technology, USA) for closing the open-end of the surrogate shell.

\subsection{Thermal imaging of the explantation culture}

Thermal imaging of the developing chicken embryo in explantation culture at embryonic Incubation Day (ID) 15 was performed to study the development of the thermoregulation of the developing embryo. Imaging was performed with a "VARIOSCAN 3021-ST" Infrared camera (from Jenoptik, Dresden, Germany). It had a temperature resolution of $\pm 0.03^{\circ}$ measured at $30^{\circ} \mathrm{C}$. Image analysis was performed with IRBIS V2.2 software provided with the system. Since such cameras image the infrared radiation from the surface, thermal imaging of the developing embryo was not possible through the calcareous shell or the opening covered with a lid. Infrared thermography allows measuring the heat radiation from the surface. It is a very sensitive method to distinguish the thermal radiation from different points on a surface. Visible light cameras image in the 450-750 $\mathrm{nm}$ range of the radiation spectrum, while Infrared cameras operate in wavelengths as long as $14 \mu \mathrm{m}$.

\subsection{Implantation of thermocouple into fertilised chicken eggs for thermal measurement of developing chicken embryo}

Thermal measurement of the developing embryo was performed by implanting fine thermocouple into a fertilised egg. Thermocouple wires were electrically insulated with a thin film of medical grade silicone (NuSil Technology, USA) and dried before the experiment. Butt-Welded Unsheathed Fine-Gauge Copper- Constantan thermocouple (Omega engineering, Daimlerstraße 26, 75392 Deckenpfronn, Germany) was connected to an "OMR-6018" 8 channels thermocouple input module (from Omega Engineering, Inc) and interfaced with computer via RS-485 port. Custom written software in LabVIEW 8.5 was used for data acquisition. Thermal measurements were plotted in a graph once every hour from the begining of incubation to external pipping (day 21 of incubation).

At the middle of the egg, a circle with a diameter of $2 \mathrm{~mm}$ was selected for thermocouple implantation site. The eggshell was grinded off with a fine diamond grinding tool leaving the egg membrane intact. The egg was rinsed with distilled water to remove grinded shell powder and wiped with a paper towel to dry. The previously prepared Silicone coated Fine-Gauge Copper- Constantan thermocouple was slowly implanted into the egg or surrogate shell taking care not to injure the egg yolk. The opening was sealed with sticky tape and the whole construct was placed into the incubator. The thermocouple was connected to the measuring system. Measurement was started nearly $1 \mathrm{~h}$ later to allow thermal stabilization. To measure the incubator temperature, a thermocouple was placed inside the incubator.

Although the temperature of the egg-contents outside the embryo do not correspond to the actual core temperature of the developing embryo (at least in the later half of incubation), but thermal measurement of the fluid surrounding the embryo (egg white and later allantoic fluid) may give a clue to the thermal status of the developing embryo.

\subsection{Lid with resistive heating for removing condensation}

Indium-tin-oxide (ITO) coated CEC020S glass was used as an optical window (from Präzisions Glas \& Optik GmbH, 
Germany). It was $1 \mathrm{~mm}$ thick, with an electrical resistance of $15 \Omega / \mathrm{sq}$. and had a $100 \mathrm{~nm}$ thick coating with ITO. It had very good optical transmission in visual region $(\approx 90 \%)$. ITO glass was glued on a PMMA ring from the top. The glass plate was heated with the flow of $20-40 \mathrm{~mA}$ DC current and the glass temperature was measured with a Pt100 thermal sensor and kept between 37.5 and $38^{\circ} \mathrm{C}$ to keep the under surface of the lid free from condensation (Fig. 7). The maximum limit was limited to $39^{\circ} \mathrm{C}$ for a short period to avoid thermal injury to the developing embryo.

2.6 Construction of the long distance fluorescence microscope for in vivo application

Fluorescence micro-imaging system was constructed with an InfinityTube ${ }^{\mathrm{TM}}$ stand in-Line assembly ${ }^{\mathrm{TM}}$ standard series (from Infinity Photo-optical company, USA) with Mitutoyo $10 \times, 33.5 \mathrm{~mm}$ ultra long working distance objective (M Plan Apo objective 378-803-2 from Mitutoyo corporation, Japan) with a 478-495 nm excitation Filter, 510-555 nm barrier filter (Blue excitation/Green emission) for green fluorescence imaging. An Illumination module was made with nine $3 \mathrm{~W}$ mini power LEDs (from Avago Technologies). LEDs have dominant wavelength of $470 \mathrm{~nm}$ and a Luminous Efficiency is $16 \mathrm{~lm} / \mathrm{W}$ each. Nine LEDs were soldered on a $20 \mathrm{~mm}$ bread board which was screwed on a round piece of aluminium with thermal paste in between for adequate heat transfer. A Sony "DFWSX910" colour firewire CCD camera was installed into the constructed micro-imaging system. The camera has an Output image size (Horizontal x Vertical) of 1,280 × 960 pixels (SXGA) and it was interfaced with the computer via "IEEE 1394-1995" Digital interface.

The XY stage was made with two units of $41.091 .036 \mathrm{C}$ high-precision linear stage, with $210 \mathrm{~mm}$ travel, 2-phase step motor and mechanical limit switches (OWIS GmbH, Germany), placed one over the other at a $90^{\circ}$ angle. The egg turning stage was made with a DMT 65 Rotary Measuring Stages (OWIS GmbH, Germany) placed on the XY stage. The Z-axis consisted of another 41.091.036 C highprecision linear stage placed vertically on the $\mathrm{XY}$ stage. The camera was mounted on the $Z$-axis. A SMS 60 motor controller (OWIS GmbH, Germany) controlled the whole system. SMS 60 was interfaced with computer via RS232 port. Custom written software in LabVIEW 7.1 was used for the stage control, camera auto focus and illumination.

\subsection{Construction of the micro-manipulation system}

The micro-manipulation system was constructed with a M3301-M3-R manual micromanipulator and tilting base (right-handed) (from World precision instruments) and a
CellTram ${ }^{\circledR}$ vario system for the microinjection and manipulation of cells (from Eppendorf, Germany). The micromanipulator had vernier scales for readings to $0.1 \mathrm{~mm} \& x$-axis fine control for readings to $10 \mu \mathrm{m}$. The control knobs project to rear located in same vertical plane. The whole system was fitted with microcapillaries transfer tip (from Eppendorf, Germany). It was connected with a multiple channel valve regulator for attaching additional microsyringe so that the system could be used not only for adding of cells but also for withdrawing of samples.

\section{Results and discussions}

\subsection{Optimisation of the lid for optical imaging}

Figure 1 shows the explantation culture of the chicken embryo in a surrogate shell covered with a Plexiglas lid. This lid has better optical properties than cling film, is easy to use and is suitable for optical imaging. The explantation culture was originally designed with a surrogate shell covered with double layer cling film. The optical properties of the cling film is not very good for imaging through. Furthermore, double layer of cling film make it even worse with trapped air in between the layers. For high resolution optical imaging, it was necessary to replace the cling film with materials with better optical property. Poly (methyl methacrylate) (PMMA) (Plexiglas), glass, and polycarbonate were used as lid of the explantation culture. Plexiglas has very good optical property. Filling the groove on the side of the Plexiglas lid with a sticky medical grade silicone enabled placing of the lid without further preparation.

We checked the durability of the constructed lid in terms of the hatchability of cultured chicken embryos. The chicken embryo explanted into a surrogate shell was closed with new Plexiglas lid and cultured until hatching.

Figure 2 shows the results of the bantam chicken embryo cultured in the new system where $\approx 77 \%$ of the birds developed normally and came to the stage of hatching which was identical to the cling film control system ( $\approx 67 \%$ ). This result shows that the evaporation through the cling film had no significant effect on the hatching rate of chicken embryos. Viable hatchlings were regarded as the parameter to test the functionality and durability of the system.

\subsection{Condensation underneath the covering lid}

Plexiglas lid is suitable for optical imaging. However, water vapour begins to condense underneath the lid which obstructs optical imaging methods. Gradually water 
Fig. 1 New lid constructions for the open avian embryo culture system. a PMMA lid with silicone adhesive, b PMMA lid with silicone adhesive containing double glass window (black arrow) and tubing for warm air circulation (white arrow). c Chicken embryo at ID 5 in an open culture system with Plexiglas covers
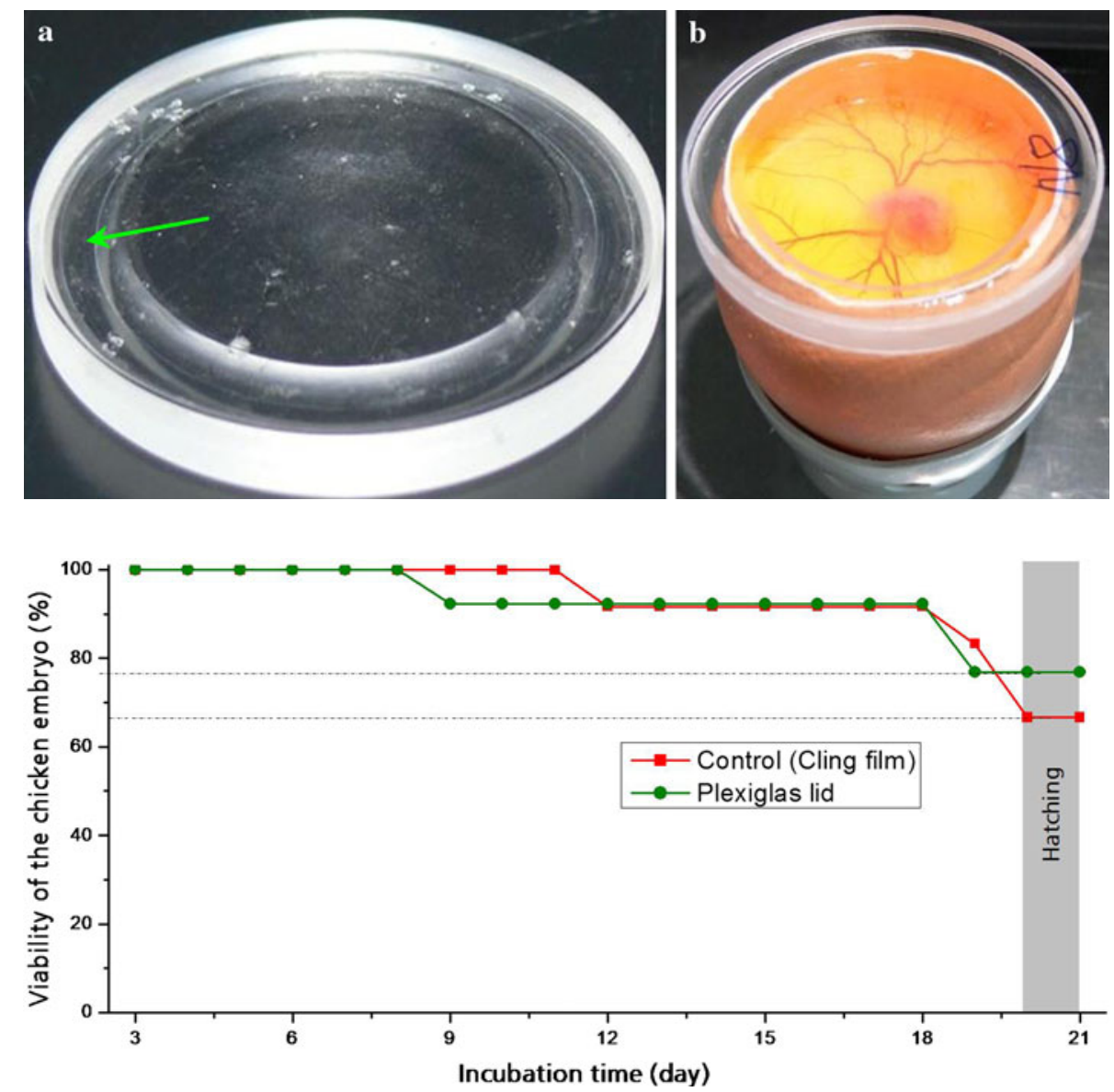

Fig. 2 Viability of chicken embryo in surrogate shell explantation culture with Plexiglas lid and cling film. $\approx 77 \%$ of the embryos developed till hatching in explantation culture with new constructed lid in contrast to $67 \%$ hatching rate with control $(\mathrm{N}$ : Control $=36$, Plexiglas lid $=30$ ) droplets appear as the embryo grows (Fig. 3). The incubator provides heat and humidity for embryonic growth and development. However, they develop their own mechanism of thermoregulation as they grow (they pass through transitional stages from poikilothermy to homeothermy in precocial species of birds). Nevertheless, with the gradual development of thermoregulation, embryos develop their core body temperature, which is higher than the incubation temperature. Condensation appears in the lid with the progress of embryonic development (Fig. 3).

From a physical point of view, the condensation is possible with a thermal gradient across the window. Temperature should be homogenous inside the incubator.
However, it is possible that, with ongoing development, embryos develop thermoregulatory mechanism. Therefore, thermal gradient develops across the optical window (inside warmer than outside) and may have caused condensation. To reveal the cause, we investigated the thermal development of the developing chicken embryo.

\subsection{Measurement of thermal development of avian embryo}

In the nature, birds incubate their eggs from above with the brood patch. The nest temperature below is lower than the incubation temperature (the skin temperature of the bird).
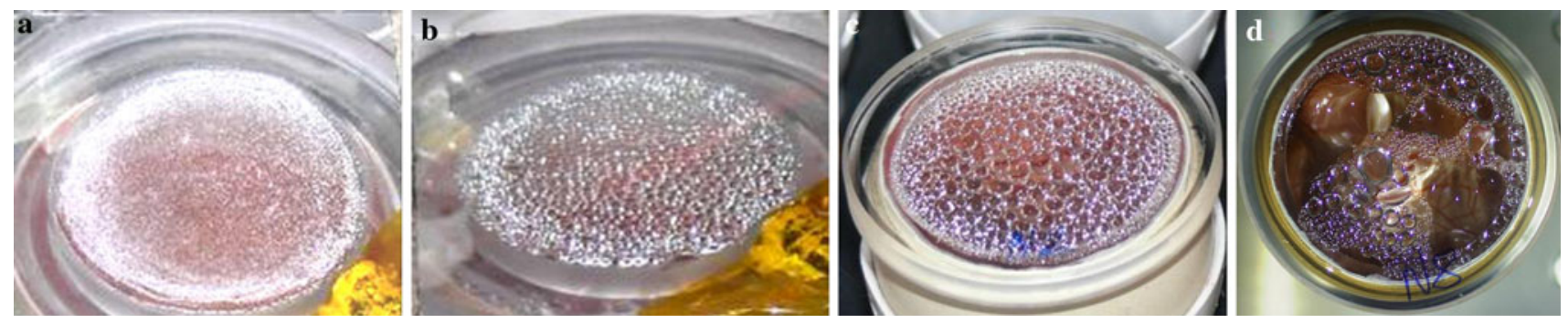

Fig. 3 Gradual appearance of condensation with the growth of the quail embryo. a ID (Incubation Day) 13, b ID 15, c ID 17, d ID 19. Note water droplet appears gradually with the development of the embryo 
The embryo floats at the top inside the egg being the blastoderm of the yolk is the lightest among egg contents. The thermal flow goes from the brood patch through the embryo downwards. On the contrary, in the incubator, the temperature is more homogenously distributed all round. Thermal measurement can provide with some information about the thermal status of the developing and nondeveloped eggs.

\subsection{Infrared thermography of the open system of avian culture}

Figure 4 shows the thermal image of the developing chicken embryos in open system at ID 15. In image (a), developing embryos show a higher temperature than the control. In the zoomed thermal image of a 15-day-old embryo in a surrogate shell (b) and control (c) shows the thermal difference between them and it is clear from the thermal image that living embryos have a higher temperature than controls. During this experiment, the incubator door was opened, and time was allowed for thermal equilibrium. During this brief period, the control (unfertilised eggs) lost the heat but the developing embryos retained.
It indicates that at this stage the embryos have developed their own thermoregulation.

\subsection{Thermal measurement of the developing chicken} embryo with thermocouple

Figure 5 shows the experimental setup for the thermal measurement of developing chicken embryos.

Figure 6 shows the results of the thermal measurement of developing avian embryos with implanted thermocouple during the whole period of avian embryogenesis.

Note that the temperature of both developed and nondeveloped eggs remains nearly half a degree Celsius lower than the incubation temperature. Temperature of the developed egg starts to rise at around ID 12 and a thermal gradient of $1-2^{\circ} \mathrm{C}$ develops gradually across the covering lid with the outside of the culture system being colder than the inside. This temperature gradient across the lid may have caused the condensation underneath the lid. The temperature of the nondeveloped eggs remains the same throughout the whole period.

A persistent thermal gradient with further embryonic growth causes condensation to become intense and it
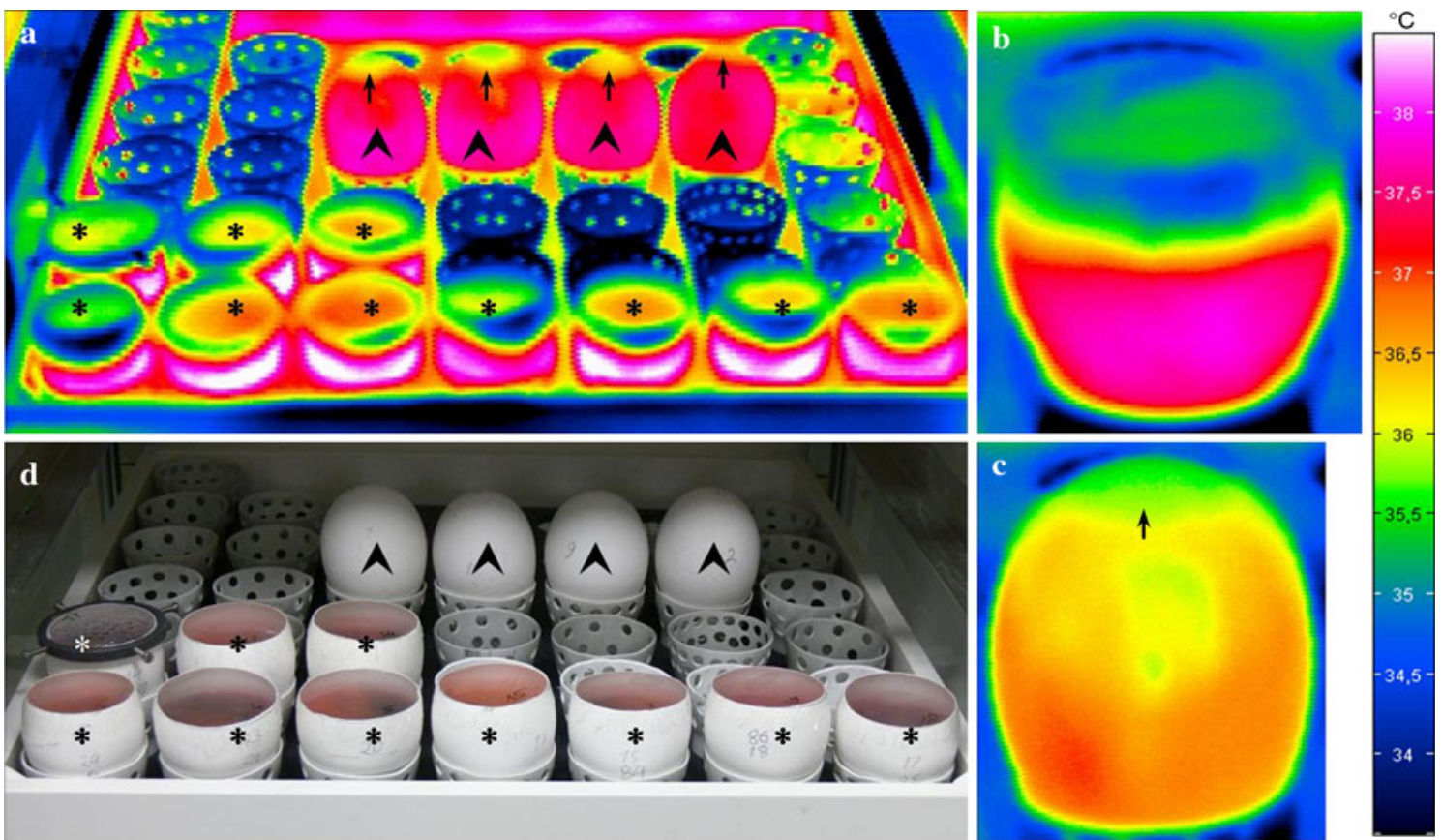

Fig. 4 Thermal imaging of developing chicken embryos. a-c Thermal imaging of the developing chicken embryo in open culture at ID 15 taken with a "VARIOSCAN 3021-ST" Infrared camera (from Jenoptik, Dresden, Germany). At this stage of development, embryos develop their own thermoregulation and they have a higher temperature than the incubation temperature. Four unfertilised eggs were place beside the growing embryos as control [black arrow head in image (a, d)]. Note in image (a), developing embryos show higher temperature [asterisks in image (a, d)] than the control (arrowhead).
In thermal image of the control, the air cells (black arrow) are also visible as areas with low temperature. In the zoomed image of the developing embryo (b) and control (c) show that the developing embryo has at least $1^{\circ} \mathrm{C}$ higher temperature than the control. In the thermal image of the embryo, the upper part of the shell shows lower temperature than the lower part because the CAM is not covering the inner surface of the surrogate shell completely, which can be seen in optical image (d) taken in the same position as the image (a) for comparison. All images were taken in the same scale 


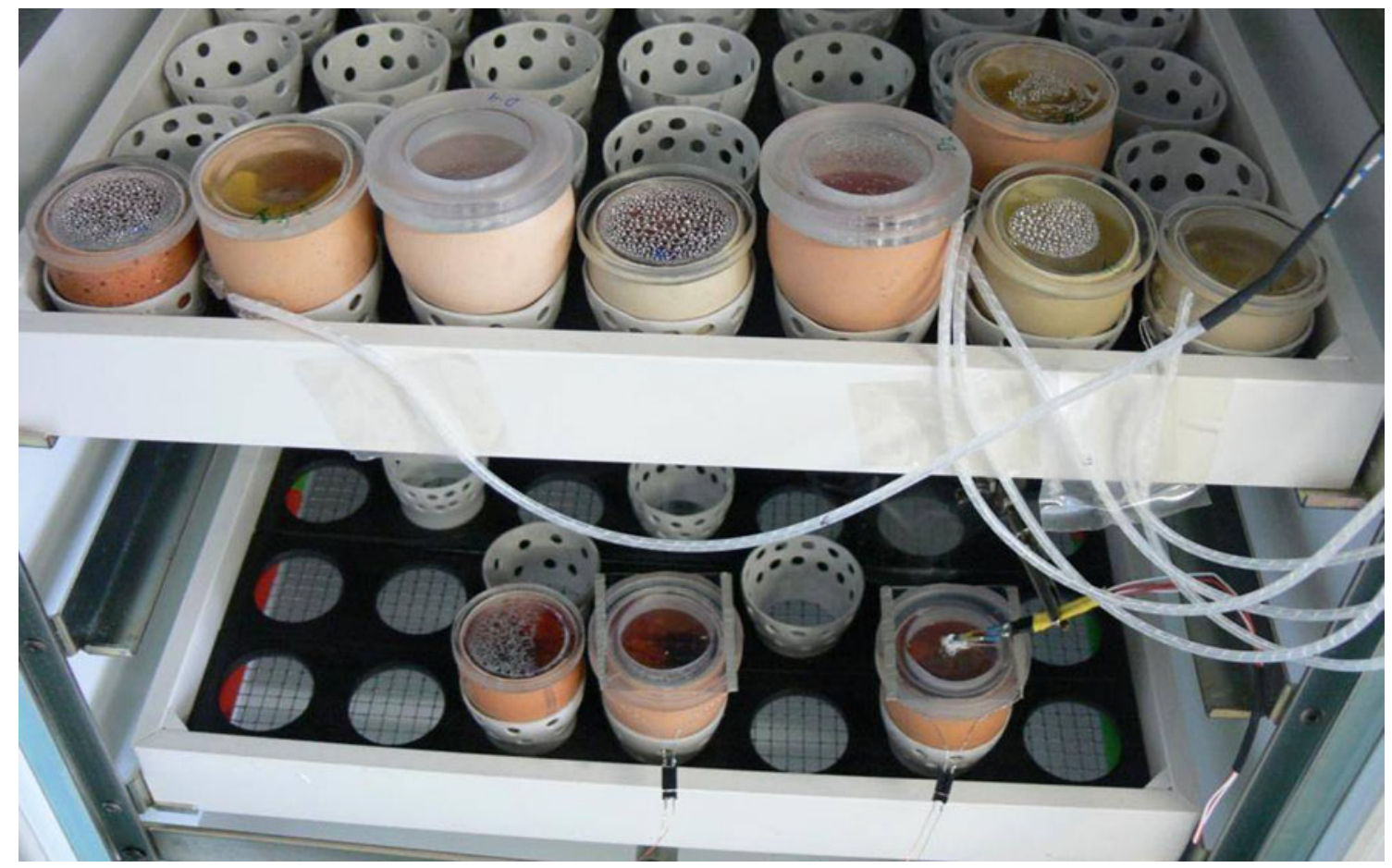

Fig. 5 Experimental setup for thermal measurement of developing chicken embryo with thermocouple. Measurement of allantoic fluid temperature as an index of deep body temperature of developing chicken embryo. Copper-constantan thermocouple was placed inside the open system of the avian culture, which was in closed contact with the developing embryo
Fig. 6 Thermal measurement of developing chicken embryo. From the graph, it is clear that a difference in temperature develops between the embryo and the incubator in the second half of the embryonic development. Note the temperature rise of the developing embryo on ID 12

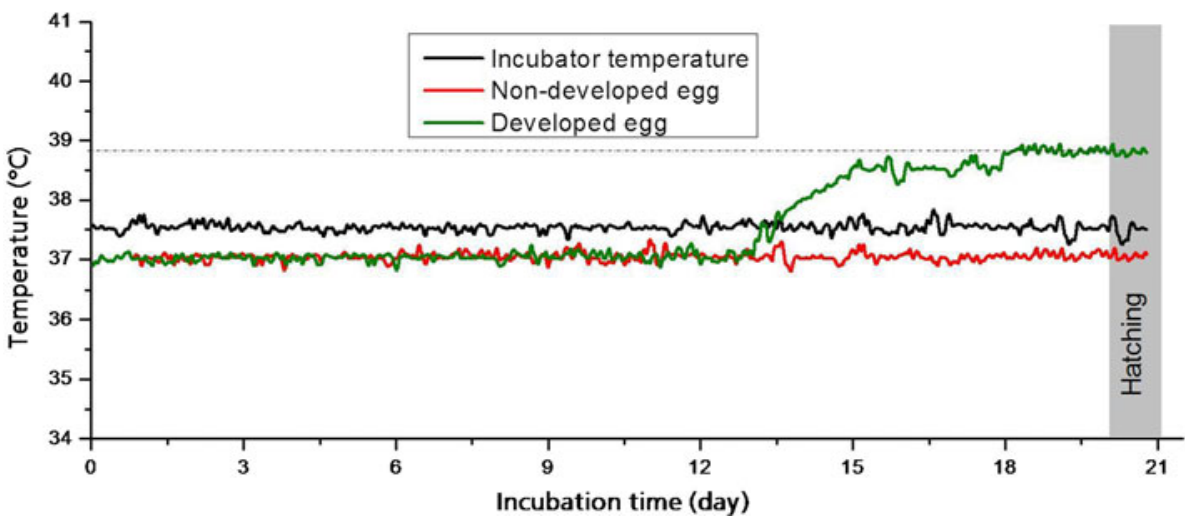

becomes difficult to see through for imaging. Later stage, water droplets begin to appear. It was necessary to develop a special lid for quick removal of condensation. This obstructs imaging not only in the later stage of incubation, but also in the early days when opening the incubator door for short time create foggy condensation which takes long time to evaporate.

\subsection{Removal of condensation: resistive heating with indium-tin-oxide coated glass cover}

Figure 7 shows the results of heating the ITO-coated glass lid carrying condensation. The window becomes clear after heating. The heating was started from the beginning to stop condensation; evaporation of the condensed water left spots on the window.

In the early days of incubation, the condensation takes considerable time to evaporates (nearly half an hour) when the temperature equalizes inside the incubator. However, for that latent period taken for evaporation of the condensed water, imaging was not possible. In the later half of incubation, the condensation remains due the thermal gradient across the lid as mentioned earlier.

To solve the problem of condensation, different approaches has been tried including antistatic optical spray on Plexiglas window, Plexiglas ring with double glass plate on top and bottom, warm airflow between two glass plates, resistive heating with electro-conductive glass plate and 
Fig. 7 Removal of condensation: resistive heating. Chick embryo in open culture at ID18; $\mathbf{a}$ before and $\mathbf{b}$ after heating. Heating was accomplished with the flow of 20-40 mA DC current through ITO coated glass. The window temperature is monitored directly using a Pt100 thermal sensor mounted on the window (arrow)
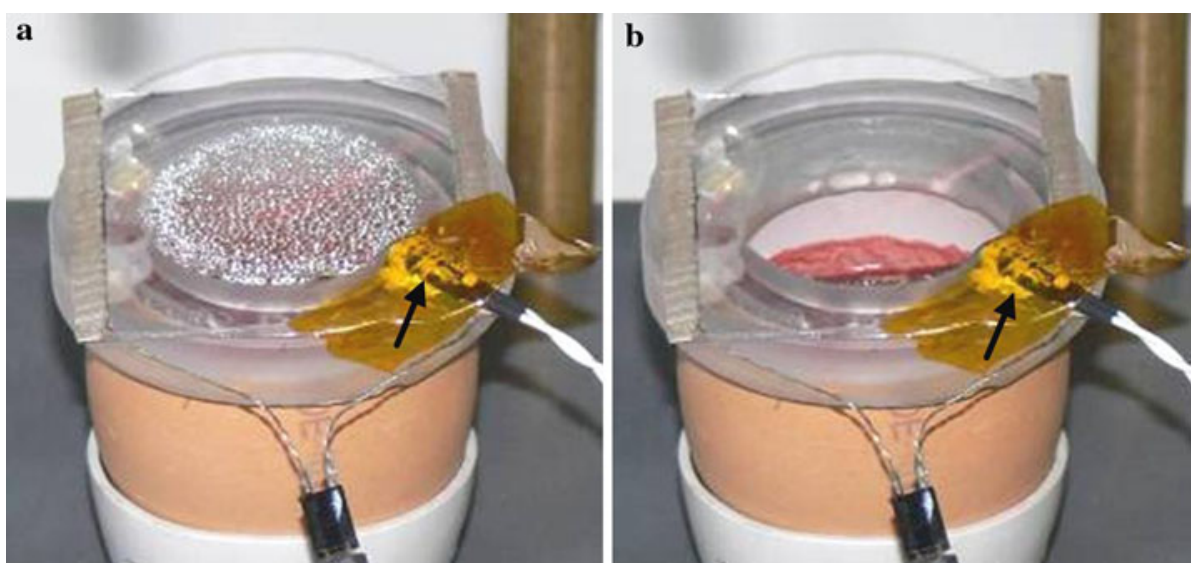

others (Fig. 8). Among them, warm airflow between the double glass plates and resistive heating with electroconductive glass plate were found to be effective. Warm airflow requires extra set up for the experiment, which is time consuming and with many samples together makes the whole procedure complicated. On the contrary, resistive heating with electro-conductive glass plate was effective, quick to setup and easy to use.

\subsection{Construction of long distance fluorescence} microscope and micromanipulation system for modified explantation culture

Figure 10 shows the complete fluorescence micro-imaging and micromanipulation system for application into modified explantation culture. It is possible to inject fluorescent labelled cells into a desired location of a developing chicken embryo and track them. Multiple locations of interest from multiple samples can be synchronously and precisely imaged at the cellular resolution throughout the complete developmental period. Functionality of the Fluorescence microimaging system was checked by imaging L929 Mouse fibroblast cells $(\approx 20 \mu \mathrm{m}$ size $)$ stained with fluoresceindiacetate (FDA) in a cell culture Petri dish (Fig. 9).
Traditional optical imaging methods provide very highresolution images. However, in most cases the short working distance of the microscope objective makes it inapplicable for imaging in an explantation culture. In addition, the culture system needs to be rocked from side to side for optimum development of the embryo. Parallel cultivation of multiple embryos and observation at the same time requires an automated sample changing and rocking device. On one hand the whole system has to be robust and reliable, while on the other hand it has to be precise in movement in the range of micrometer for imaging at cellular level. The imaging has to be performed on both micro and macro scale; screening the whole embryo with a macro lens leads to discovering the desired location for microimaging. Continuous illumination may have detrimental influence on embryonic development (Tamimie 1967). For long-term time lapse imaging, it is therefore necessary to turn on the illumination only during the imaging procedure and turn off afterwards. Traditional microscopes use incandescent or mercury-vapour lamps for illumination. Such lamps produce very intense light, which is then filtered to have the desired frequency. However, they take quite a while to warm-up for emitting adequate intensity of light. It is very difficult to switch on and off such lamps within a short period.
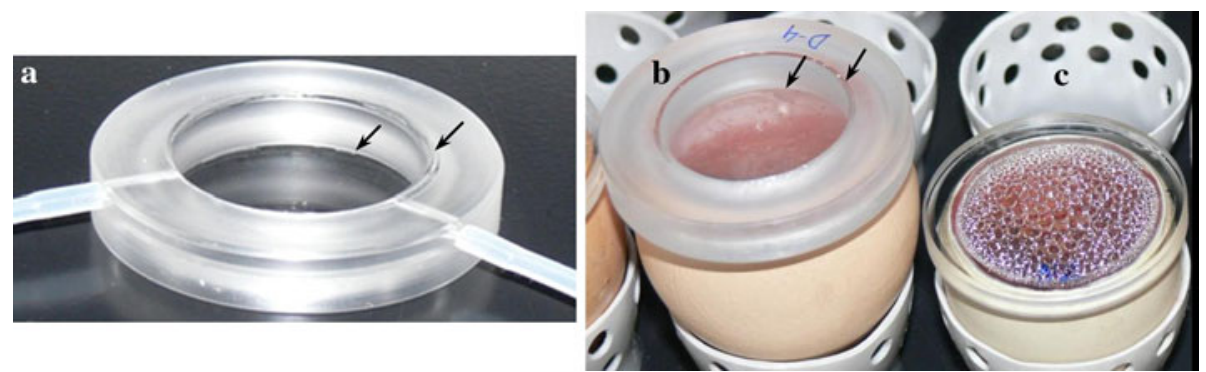

Fig. 8 Different lid construction for the removal of condensation. a Plexiglas lid with double glass window with possibility of warm air flow between the layers; $\mathbf{b}$ plexiglas ring with double glass plate on top and bottom; c plexiglas lid with silicone. Image (b) and (c) shows

the effect of condensation under different types of lid construction at 14 day old embryo. Mark in image (b) (double glass window), condensation is less than normal Plexiglas lid (c), but not good enough for imaging 


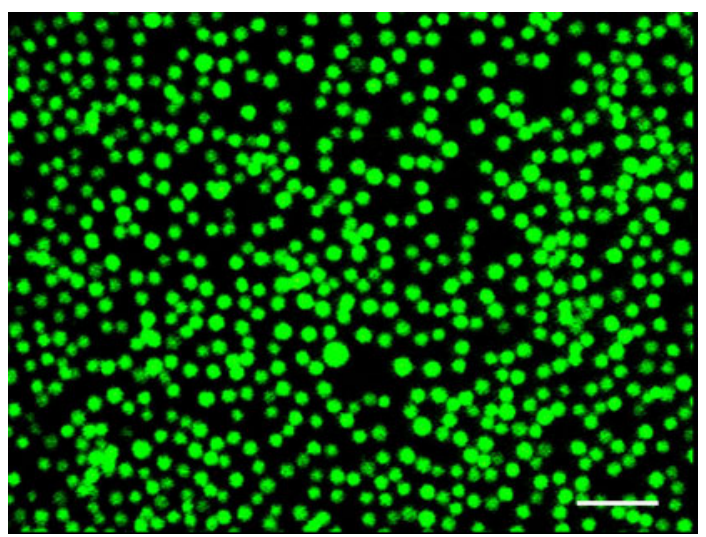

Fig. 9 L929 Mouse fibroblast cells stained with fluoresceindiacetate (FDA) in a cell culture Petridish and imaged with especial long distance fluorescence microimaging system constructed for ex ovo application in a technically modified explantation culture consisting of surrogate shell. Scale bar $=100 \mu \mathrm{m}$

The explantation culture of avian embryo was technically modified and optimised for optical imaging. The yolk is the lightest part of the egg contents (specific gravity of egg yolk is 1.029, thick albumen 1.036 and thin albumen 1.040) (Suda et al. 1994). The chemical composition of the thick and thin albumen is similar (Cunningham et al. 1960) but the thick albumen is richer in ovomucin and ovomucin is responsible for the elevated viscosity (Sturkie 1976). Moreover, the specific gravity of thin albumen is lower than that of the thick albumen and also that of the egg yolk. During these periods, the differences in the specific gravity among the yolk, thick albumen and thin albumen play a very important role in the normal development of chicken embryos (Suda et al. 1994). Blastoderm is the lightest part of the yolk and is therefore floating at the top. Following embryo transfer, the surrogate shell was filled with thin albumen, leaving nearly $10 \mathrm{~mm}$ depth from the brim so that the embryo and the CAM do not touch the lid during rocking (Fig. 11). For optimum imaging, good illumination is necessary; space is required between the objective and the covering lid for illumination for reflection imaging.

It was possible to image the whole period of chicken embryo development from blastoderm stage until hatching by using the modified explantation culture system and constructed long distance microscope. The video is supplied as a supplementary document. Time lapse movie was constructed by taking snap shots of the blastoderm surface every $5 \mathrm{~min}$. Due to excessive embryonic movement during the second week of development and later, representative still images are shown in the video for a better demonstration. Still images from the time lapse video are shown in Fig. 12. The embryo developed normally and hatched during the imaging process indicating that there was no detrimental effect on embryonic development. Injection of fluorescence labelled stem cells into a chicken embryo and tracking them in vivo with the constructed systems may revolutionize the field of stem cell research.

\section{Conclusion}

A cheap and easy model system for in vivo study of stem cell migration and differentiation in real time has been
Fig. 10 Fluorescence microimaging and micromanipulation system constructed for in ovo application. Long working distance microscope mounted on high-precision linear stage; blue rectangle $=$ SMS 60 motor controller for controlling the microscope stage and camera auto focus; $\mathrm{R}=$ computer controlled XY stage for placement of culture systems for imaging; $\mathrm{C}=$ camera mounted on the microscope; inset (upper left $)=$ LED illumination module for fluorescence microscopy; inset (lower $l e f t)=$ microfluidic controller

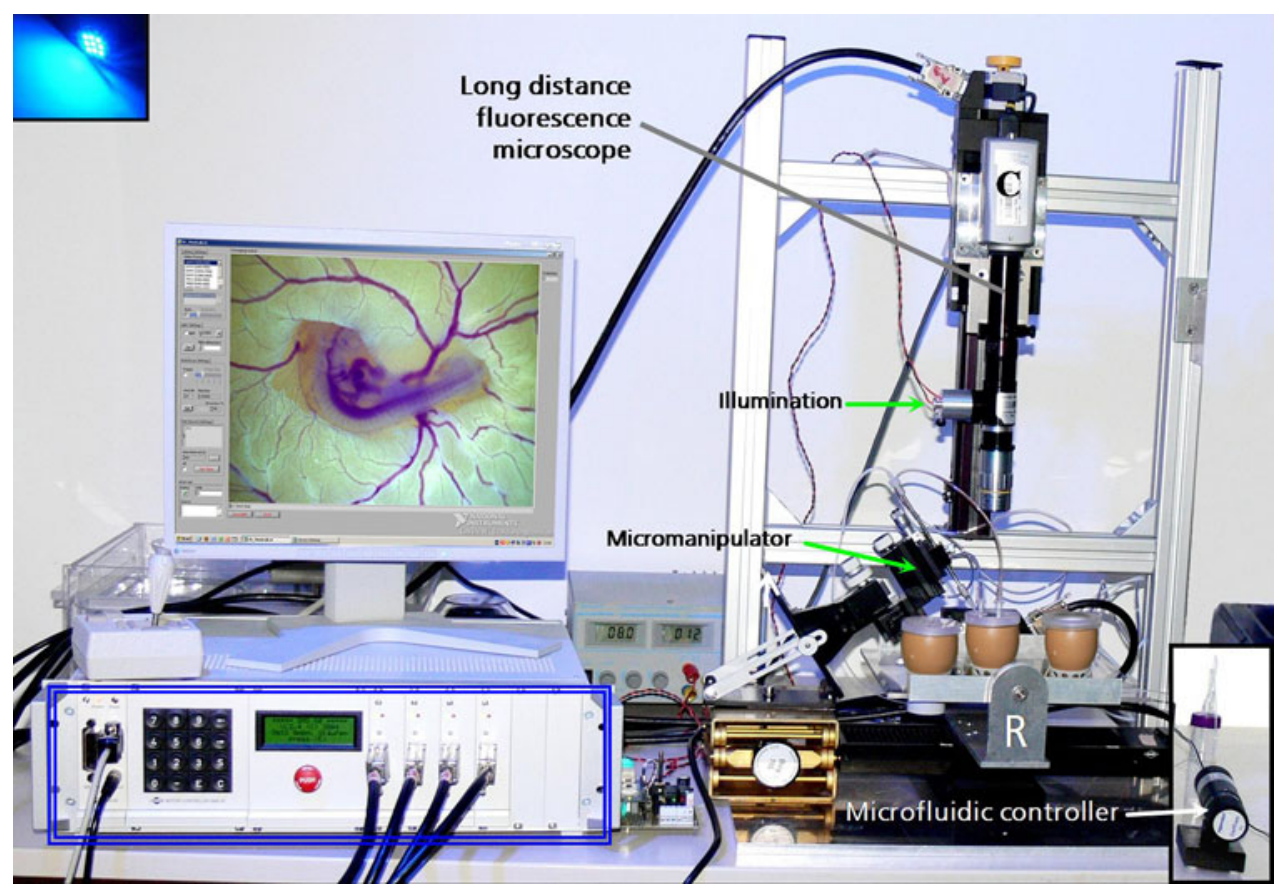


Fig. 11 Relative position of the different components of avian egg in explantation culture. a Computer simulation of egg contents (sectional view) shows the blastoderm floating at the top of the egg contents; b a 4-day-old chicken embryo is explanted in a transparent artificial culture system showing the developing embryo is

floating at the top. Inside avian eggs, the yolk is kept in position by chalazae, the yolk can rotate with the influence of gravitation, and the blastoderm takes it upper position being the lightest of all
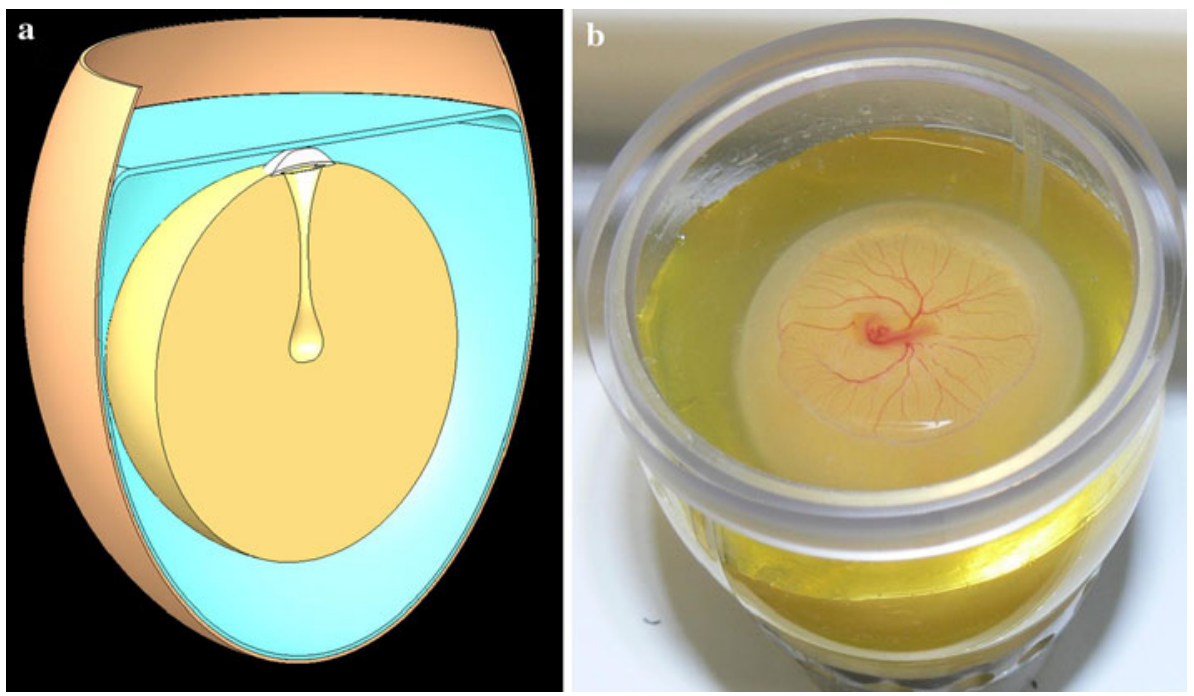
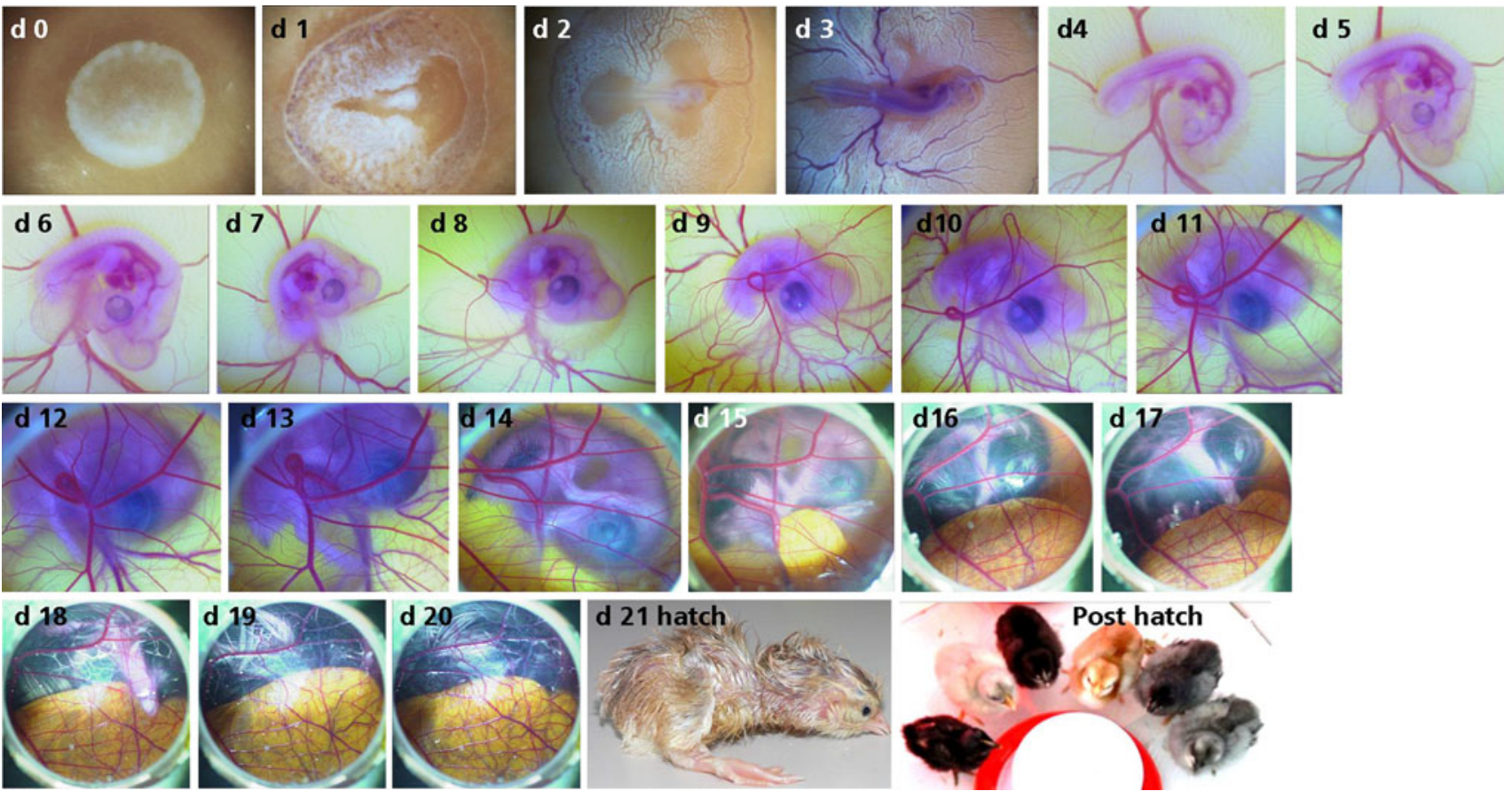

Fig. 12 Still images taken from the time lapse video of the complete chicken development was placed in this figure for demonstration. It is important to note that the posture of the embryo and image contrast changed during the whole period of development due to extensive embryonic movement at later phase of development and resuscitation

developed. Developing chicken embryos offer an in vivo system with many advantages over other animals for studying stem cell migration and differentiation, like a lower cost, lack of a functional immune system, easy and simple access to the in vivo processes and many more. Despite not being a complete substitute for standard animal models, the number of necessary animal experiments for in vivo analysis can be drastically reduced by using this model system. Application of such systems will lead to the of the embryo during hatching. Note the embryo is relatively transparent during the early developmental phase which is extremely helpful for the tracking the fluorescence labelled cells injected into the embryo

enrichment of existing knowledge in the field of cell biology, stem cell research, as well as tissue engineering. It is very important to have such an in vivo system to study cell physiology, since it is very difficult to realise cell physiology from in vitro experiments. Experimental results from in vivo system are closer to physiological state than in vitro experiments. This is a large field with great potential, and we are just in the beginning to explore it. Although, it is difficult to predict the outcome of the human 
experiments from the results of in vivo experiments in animal models, it may help to anticipate and plan for further experiments.

Acknowledgments This work was supported by Fraunhofer Institute for Biomedical Engineering (IBMT) in St.Ingbert, Germany. We gratefully acknowledge Dr. Robert Johan, Dr. Dominik Lermen and Auernheimer Vera from Fraunhofer IBMT, in St. Ingbert, Germany for their assistance.

Open Access This article is distributed under the terms of the Creative Commons Attribution Noncommercial License which permits any noncommercial use, distribution, and reproduction in any medium, provided the original author(s) and source are credited.

\section{References}

Allaire E, Muscatelli-Groux B, Mandet C, Guinault AM, Bruneval P, Desgranges P, Clowes A, Melliere D, Becquemin JP (2002) Paracrine effect of vascular smooth muscle cells in the prevention of aortic aneurysm formation. J Vasc Surg 36(5):1018-1026

Amariglio N, Hirshberg A, Scheithauer BW, Cohen Y, Loewenthal R, Trakhtenbrot L, Paz N, Koren-Michowitz M, Waldman D, Leider-Trejo L, Toren A, Constantini S, Rechavi G (2009) Donor-derived brain tumor following neural stem cell transplantation in an ataxia telangiectasia patient. PLoS Med 6(2):e1000029

Anders M, Hansen R, Ding RX, Rauen KA, Bissell MJ, Korn WM (2003) Disruption of 3D tissue integrity facilitates adenovirus infection by deregulating the coxsackievirus and adenovirus receptor. Proc Natl Acad Sci USA 100(4):1943-1948

Arbab AS, Bashaw LA, Miller BR, Jordan EK, Lewis BK, Kalish H, Frank JA (2003) Characterization of biophysical and metabolic properties of cells labeled with superparamagnetic iron oxide nanoparticles and transfection agent for cellular MR imaging. Radiology 229(3):838-846

Beauvais-Jouneau A, Pla P, Bernex F, Dufour S, Salamero J, Fassler R, Panthier JJ, Thiery JP, Larue L (1999) A novel model to study the dorsolateral migration of melanoblasts. Mech Dev 89(1-2):3-14

Borges J, Tegtmeier FT, Padron NT, Mueller MC, Lang EM, Stark GB (2003) Chorioallantoic membrane angiogenesis model for tissue engineering: a new twist on a classic model. Tissue Eng 9(3):441-450

Cashman JD, Lapidot T, Wang JC, Doedens M, Shultz LD, Lansdorp P, Dick JE, Eaves CJ (1997) Kinetic evidence of the regeneration of multilineage hematopoiesis from primitive cells in normal human bone marrow transplanted into immunodeficient mice. Blood 89(12):4307-4316

Clarke DL, Johansson CB, Wilbertz J, Veress B, Nilsson E, Karlstrom H, Lendahl U, Frisen J (2000) Generalized potential of adult neural stem cells. Science 288(5471):1660-1663

Cunningham FE, Cotterill OJ, Funk EM (1960) The effect of season and age of bird. 1. On egg size, quality and yield. Poult Sci 39:289-299

Dowell JD, Rubart M, Pasumarthi KB, Soonpaa MH, Field LJ (2003) Myocyte and myogenic stem cell transplantation in the heart. Cardiovasc Res 58(2):336-350

Ettensohn CA (1985) Gastrulation in the sea urchin embryo is accompanied by the rearrangement of invaginating epithelial cells. Dev Biol 112(2):383-390

Flax JD, Aurora S, Yang C, Simonin C, Wills AM, Billinghurst LL, Jendoubi M, Sidman RL, Wolfe JH, Kim SU, Snyder EY (1998)
Engraftable human neural stem cells respond to developmental cues, replace neurons, and express foreign genes. Nat Biotechnol 16(11):1033-1039

Fontaine-Perus J, Halgand P, Cheraud Y, Rouaud T, Velasco ME, Cifuentes Diaz C, Rieger F (1997) Mouse-chick chimera: a developmental model of murine neurogenic cells. Development 124(16):3025-3036

Fuchs E, Segre JA (2000) Stem cells: a new lease on life. Cell 100(1):143-155

Gibbs N (2006) Stem cells. The hope and the hype. Time 168(6):4046

Goldenthal MJ, Marin-Garcia J (2003) Stem cells and cardiac disorders: an appraisal. Cardiovasc Res 58(2):369-377

Goldstein RS, Drukker M, Reubinoff BE, Benvenisty N (2002) Integration and differentiation of human embryonic stem cells transplanted to the chick embryo. Dev Dyn 225(1):80-86

Gustafson T, Wolpert L (1967) Cellular movement and contact in sea urchin morphogenesis. Biol Rev Camb Philos Soc 42(3): 442-498

He JQ, Ma Y, Lee Y, Thomson JA, Kamp TJ (2003) Human embryonic stem cells develop into multiple types of cardiac myocytes: action potential characterization. Circ Res 93(1): 32-39

Jiang Y, Jahagirdar BN, Reinhardt RL, Schwartz RE, Keene CD, Ortiz-Gonzalez XR, Reyes M, Lenvik T, Lund T, Blackstad M, $\mathrm{Du}$ J, Aldrich S, Lisberg A, Low WC, Largaespada DA, Verfaillie CM (2002) Pluripotency of mesenchymal stem cells derived from adult marrow. Nature 418(6893):41-49

Keller G, Snodgrass HR (1999) Human embryonic stem cells: the future is now. Nat Med 5(2):151-152

Kimmel CB, Law RD (1985) Cell lineage of zebrafish blastomeres. I. Cleavage pattern and cytoplasmic bridges between cells. Dev Biol 108(1):78-85

Klueh U, Dorsky DI, Moussy F, Kreutzer DL (2003) Ex ova chick chorioallantoic membrane as a novel model for evaluation of tissue responses to biomaterials and implants. J Biomed Mater Res A 67(3):838-843

Kocher AA, Schuster MD, Szabolcs MJ, Takuma S, Burkhoff D, Wang J, Homma S, Edwards NM, Itescu S (2001) Neovascularization of ischemic myocardium by human bone-marrowderived angioblasts prevents cardiomyocyte apoptosis, reduces remodeling and improves cardiac function. Nat Med 7(4):430-436

Kuehnle I, Goodell MA (2002) The therapeutic potential of stem cells from adults. BMJ 325(7360):372-376

Liechty KW, MacKenzie TC, Shaaban AF, Radu A, Moseley AM, Deans R, Marshak DR, Flake AW (2000) Human mesenchymal stem cells engraft and demonstrate site-specific differentiation after in utero transplantation in sheep. Nat Med 6(11):1282-1286

Martinez-Madrid B, Donnez J, Van Eyck AS, Veiga-Lopez A, Dolmans MM, Van Langendonckt A (2009) Chick embryo chorioallantoic membrane (CAM) model: a useful tool to study short-term transplantation of cryopreserved human ovarian tissue. Fertil Steril 91(1):285-292

McKay R (2000) Stem cells-hype and hope. Nature 406(6794): 361-364

Niklason LE, Langer R (2001) Prospects for organ and tissue replacement. JAMA 285(5):573-576

Orlic D, Kajstura J, Chimenti S, Bodine DM, Leri A, Anversa P (2003) Bone marrow stem cells regenerate infarcted myocardium. Pediatr Transplant 7(Suppl 3):86-88

Ozawa T, Mickle DA, Weisel RD, Koyama N, Ozawa S, Li RK (2002) Optimal biomaterial for creation of autologous cardiac grafts. Circulation 106(12 Suppl 1):176-182

Paul G, Li JY, Brundin P (2002) Stem cells: hype or hope? Drug Discov Today 7(5):295-302 
Perry MM (1988) A complete culture system for the chick embryo. Nature 331(6151):70-72

Reubinoff BE, Pera MF, Fong CY, Trounson A, Bongso A (2000) Embryonic stem cell lines from human blastocysts: somatic differentiation in vitro. Nat Biotechnol 18(4):399-404

Ribatti D, Vacca A, Ranieri G, Sorino S, Roncali L (1996) The chick embryo chorioallantoic membrane as an in vivo wound healing model. Pathol Res Pract 192(10):1068-1076

Ribatti D, Vacca A, Roncali L, Dammacco F (2000) The chick embryo chorioallantoic membrane as a model for in vivo research on anti-angiogenesis. Curr Pharm Biotechnol 1(1):73-82

Ribatti D, Nico B, Vacca A, Roncali L, Burri PH, Djonov V (2001) Chorioallantoic membrane capillary bed: a useful target for studying angiogenesis and anti-angiogenesis in vivo. Anat Rec 264(4):317-324

Richardson M, Singh G (2003) Observations on the use of the avian chorioallantoic membrane (CAM) model in investigations into angiogenesis. Curr Drug Targets Cardiovasc Haematol Disord 3(2):155-185

Rowlett K, Simkiss K (1987) Explanted embryo culture: in vitro and in ovo techniques for domestic fowl. Br Poult Sci 28(1):91-101

Senior K (1999) Human embryonic stem cells: the future of transplantation medicine? Mol Med Today 5(2):47-48

Sigurjonsson OE, Perreault MC, Egeland T, Glover JC (2005) Adult human hematopoietic stem cells produce neurons efficiently in the regenerating chicken embryo spinal cord. Proc Natl Acad Sci USA 102(14):5227-5232

Sturkie PD (1976) Avian physiology. Springer, New York

Suda T, Abe E, Shinki T, Katagiri T, Yamaguchi A, Yokose S, Yoshiki S, Horikawa H, Cohen GW, Yasugi S et al (1994) The role of gravity in chick embryogenesis. FEBS Lett $340(1-2): 34-38$

Sulston JE, Schierenberg E, White JG, Thomson JN (1983) The embryonic cell lineage of the nematode Caenorhabditis elegans. Dev Biol 100(1):64-119

Taizi M, Deutsch VR, Leitner A, Ohana A, Goldstein RS (2006) A novel and rapid in vivo system for testing therapeutics on human leukemias. Exp Hematol 34(12):1698-1708

Tamimie HS (1967) Light exposure of incubating eggs and its influence of the growth of chicks. I. Brooding chicks under different light regimens. Comp Biochem Physiol 21(1):59-63

Taylor DA, Silvestry SC, Bishop SP, Annex BH, Lilly RE, Glower DD, Kraus WE (1997) Delivery of primary autologous skeletal myoblasts into rabbit heart by coronary infusion: a potential approach to myocardial repair. Proc Assoc Am Physicians 109(3):245-253

Toma C, Pittenger MF, Cahill KS, Byrne BJ, Kessler PD (2002) Human mesenchymal stem cells differentiate to a cardiomyocyte phenotype in the adult murine heart. Circulation 105(1):93-98

Trinkaus JP (1996) Ingression during early gastrulation of fundulus. Dev Biol 177(1):356-370

Tsonis PA (2002) Regenerative biology: the emerging field of tissue repair and restoration. Differentiation 70(8):397-409

Valdes TI, Kreutzer D, Moussy F (2002) The chick chorioallantoic membrane as a novel in vivo model for the testing of biomaterials. J Biomed Mater Res 62(2):273-282

Valdes TI, Klueh U, Kreutzer D, Moussy F (2003) Ex ova chick chorioallantoic membrane as a novel in vivo model for testing biosensors. J Biomed Mater Res A 67(1):215-223

Wang F, Weaver VM, Petersen OW, Larabell CA, Dedhar S, Briand P, Lupu R, Bissell MJ (1998) Reciprocal interactions between betal-integrin and epidermal growth factor receptor in threedimensional basement membrane breast cultures: a different perspective in epithelial biology. Proc Natl Acad Sci USA 95(25): 14821-14826

Weaver VM, Petersen OW, Wang F, Larabell CA, Briand P, Damsky C, Bissell MJ (1997) Reversion of the malignant phenotype of human breast cells in three-dimensional culture and in vivo by integrin blocking antibodies. J Cell Biol 137(1):231-245

White PM, Anderson DJ (1999) In vivo transplantation of mammalian neural crest cells into chick hosts reveals a new autonomic sublineage restriction. Development 126(19):4351-4363

Wolf K, Mazo I, Leung H, Engelke K, von Andrian UH, Deryugina EI, Strongin AY, Brocker EB, Friedl P (2003) Compensation mechanism in tumor cell migration: mesenchymal-amoeboid transition after blocking of pericellular proteolysis. J Cell Biol 160(2):267-277

Yoo KJ, Li RK, Weisel RD, Mickle DA, Jia ZQ, Kim EJ, Tomita S, Yau TM (2000) Heart cell transplantation improves heart function in dilated cardiomyopathic hamsters. Circulation 102(19 Suppl 3):204-209

Zwadlo-Klarwasser G, Gorlitz K, Hafemann B, Klee D, Klosterhalfen B (2001) The chorioallantoic membrane of the chick embryo as a simple model for the study of the angiogenic and inflammatory response to biomaterials. J Mater Sci Mater Med 12(3):195-199 